\title{
The Effect of Humorous Stimuli on Alleviating Pain during Mammography: A Preliminary Study
}

\author{
Yongbum Lee, Mieko Uchiyama \\ Graduate School of Health Sciences, Niigata University, Niigata, Japan \\ Email: lee@clg.niigata-u.ac.jp, uchiyama@clg.niigata-u.ac.jp
}

Received 7 May 2015; accepted 2 June 2015; published 5 June 2015

Copyright (C) 2015 by authors and Scientific Research Publishing Inc.

This work is licensed under the Creative Commons Attribution International License (CC BY).

http://creativecommons.org/licenses/by/4.0/

(c) (i) Open Access

\begin{abstract}
Mammography is widely performed as a standardized procedure for breast cancer screening; however, women often feel some degree of pain during this procedure. Currently, there are limited options available for alleviating pain related to mammography. A non-medicinal approach to the alleviation of pain involves the effects of laughter on physical and psychological wellbeing. We therefore examined the possibility that humorous stimuli would alleviate the physical burden on women undergoing mammography. We assessed 29 women, 15 women received only conventional mammography (neutral group), while 14 women (humor group) watched a funny video during the same examination. The intensity of pain experienced during mammography was assessed by visual analogue scale (VAS) and the VAS results showed a statistically significant difference $(P=0.007)$ between the two groups, with the humor group experiencing less pain. In an additional experiment, 14 women in the humor group also underwent conventional mammography without exposure to the funny video and pain was assessed by VAS. We found that the pain experienced during conventional mammography without the funny video was significantly greater than the pain experienced during the same mammography but with the funny video $(P=0.047)$. These findings suggested the possibility of alleviating pain during mammography by humorous stimuli.
\end{abstract}

\section{Keywords}

Mammography, Pain Alleviation, Humorous Stimuli, Visual Analogue Scale

\section{Introduction}

Mammography screening, which is considered to be of the greatest benefit for the early detection of breast can- 
cer, is widely performed as a standardized procedure [1] [2]. Mammography is a radiological test during which the breast is compressed by parallel plates to make the breast tissue as even and thin as possible. However, it is well known that mammography screening is physically taxing. Along with compression of the breast, positioning during mammography such as twisting the neck and keeping the arms elevated is burdensome. Many women feel the physical burden during mammography as pain [3]-[7], which may contribute to a woman's feeling of anxiety about the examination [6] [7]. Appropriate techniques for radiography and management of the mammography device to obtain accurate images have been established. This has made it possible to obtain good radiographic images of the breast [8]-[11]. However, studies are lacking on objective methods to measure the physical burden on women and the alleviation of pain during the examination, such studies are needed in the future [12].

Assessments of pain experienced during mammography were made by Sharp et al. [13] using a visual analog scale (VAS) [14] [15] and by Hafslund et al. [6] using the McGill pain questionnaire (MPQ) [16]. The MPQ could be considered as the most famous pain assessment tool. However, the VAS is perhaps the most widely used instrument for the measurement of pain intensity because it is a simple, robust, sensitive, and reproducible instrument in such a way that it can be given a numerical value to the pain intensity. Furthermore, whereas the VAS takes only a few minutes to be understood and filled in, MPQ administration requires about 15 minutes [17]. Both the VAS and MPQ are methods for subjectively assessing pain. Conversely, Uchiyama et al. [18] [19] objectively quantified the physical burden on female subjects by measuring the electrical potential generated by the activation of certain muscle groups, including the trapezius and sternocleidomastoid muscles, which are associated with positioning during mammography. In addition, Uchiyama et al. [20] assessed the level of psychological stress by measuring heart rate variability. As to the alleviation of pain, Tabar et al. [21] and Markle et al. [22] reported on the usefulness of radiolucent cushions, but because these cushions are single-use, their use is debatable because of the high cost. Patient-controlled compression was tested by Kornguth et al. [23] as a method to alleviate pain. With this method, one of the breasts was compressed by a radiographer and the other was compressed by the participant. In $71 \%$ of the participants, self-compression resulted in significantly less pain than compression by a radiographer without a difference in the adequacy of the image quality and compression of the breast. There are limited options currently available for alleviating pain related to mammography and further research will be needed to address this problem.

As an alternative, non-medicinal approach was reported by Cousins in the 1970s [24], who examined the effects of laughter on physical and psychological wellbeing and the alleviation of pain. Cousins had an incurable disease, which had only a 1 in 500 chance of a full recovery through the medical care available at that time. However, when he had a good laugh by watching a funny film for 10 minutes, he could sleep well without pain for at least 2 hours. Since then, the effects of laughter on the mind and body have been discussed [25] [26]. For example, Adams et al. [27] showed that the quality of life improved in the elderly living in a day care facility when they watched humorous films. Rotton et al. [28] reported that dosages of drugs to relieve pain were reduced in patients who watched a funny video after surgery. Nove et al. [29] and Weisenberg et al. [30] showed that pain tolerance, which was measured by the cold pressor test, was significantly increased among patients who viewed a humorous film. These studies indicate that laughter is good medicine for pain.

We therefore considered that the physical burden on women associated with mammography might be alleviated by humorous stimuli and we performed a preliminary study to investigate this possibility. Here we described the experimental method and outcome to validate the hypothesis that humor stimuli could reduce pain sensation during mammography.

\section{Methods}

Volunteers were solicited for this study through poster advertisements, leaflets, and a website. From those who contacted us, we chose 29 healthy women, whose mean age \pm standard deviation (SD) was $33.4 \pm 6.5$ years, height was $158.4 \pm 5.3 \mathrm{~cm}$, weight was $53.5 \pm 9.1 \mathrm{~kg}$, and body mass index was $21.2 \pm 3.5 \mathrm{~kg} / \mathrm{m}^{2}$. Ten of the 29 women had previously experienced mammography, and the remaining 19 had not. The participants were given an explanation of the study objectives, methods, and safety, and their informed consent was obtained. This study was conducted with the approval of the research ethics committee at Graduate school of Health Sciences, Niigata University.

Observation in the study began when the right breast was in final position, which included compression but 
excluded X-ray irradiation, for mediolateral oblique (MLO) imaging. Participants were divided into two groups according to whether or not they viewed a video of humorous clips during the procedure. Fifteen participants were designated as the neutral group and 14 were designated as the humor group. The mean force of breast compression was $122 \pm 12 \mathrm{~N}$.

We collected some funny clips and then edited them to make a video. It had been confirmed previously that, using the same video, pain tolerance significantly increased when subjects underwent the cold pressor test [29] [30]. Study participants in the humor group watched the video for $2 \mathrm{~min}$ on a head-mounted display (Wrap 1200 Video Eyewear, VUZIX, Rochester, NY) at rest and then continuously watched the video during mammography.

The degree of pain during the mammogram was measured by a VAS shortly after the examination. In the humor group, comicality of the video and distraction along with pain were also measured by VAS. Figure 1 shows the VAS designed for this study. The VAS was used to assign a score from 0 on the left extreme (no pain) to 10 on the right extreme (worst possible pain) with a possible score of 10 for each element examined. The Mann-Whitney U test was used to determine if differences between the two groups were statistically significant.

\section{Results}

Table 1 shows the VAS results, and the box-and-whisker plot obtained from the VAS scores indicates the degree of pain (Figure 2). The VAS scores indicating the degree of pain in the neutral group and humor group were $7.3 \pm 2.6$ and $4.9 \pm 2.2$, respectively (Table 1 ). The VAS scores indicating the degree of distraction and comicality of the video in the humor group were $5.8 \pm 2.8$ and $5.4 \pm 2.1$, respectively (Table 1). Although the difference in pain between the neutral and humor groups was statistically significant $(P=0.007$, Figure 2$)$, the Spearman's rank correlation coefficient for pain and comicality was $\rho=0.15$, and the difference between pain and comicality was therefore not statistically significant $(P=0.61)$. Likewise, the Spearman's rank correlation coefficient for pain and distraction in the humor group was $\rho=0.19$, and the difference between pain and distraction in the humor group was not statistically significant $(P=0.51)$.

\section{Discussion}

In general, the funnier the video, the more frequently do people laugh. Our participants appeared to be distracted

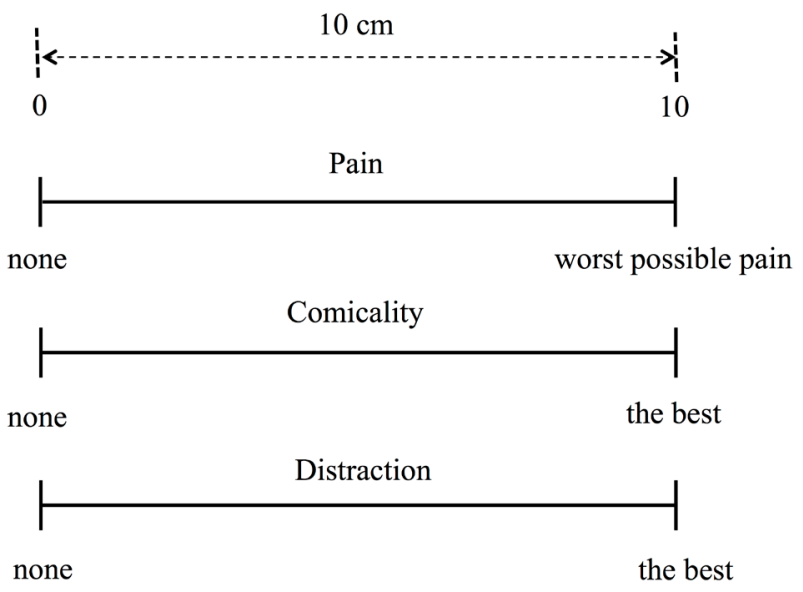

Figure 1. Visual analog scale designed for this study.
\begin{tabular}{cccc} 
Table 1. Visual analog scale findings in the neutral and humor groups. \\
\hline Pain & Comicality & Distraction \\
\hline Neutral group & $7.3 \pm 2.6$ & & \\
Humor group & $4.9 \pm 2.2$ & $5.4 \pm 2.1$ & $5.8 \pm 2.8$ \\
\hline
\end{tabular}

Values are presented as mean \pm standard deviation (SD). 


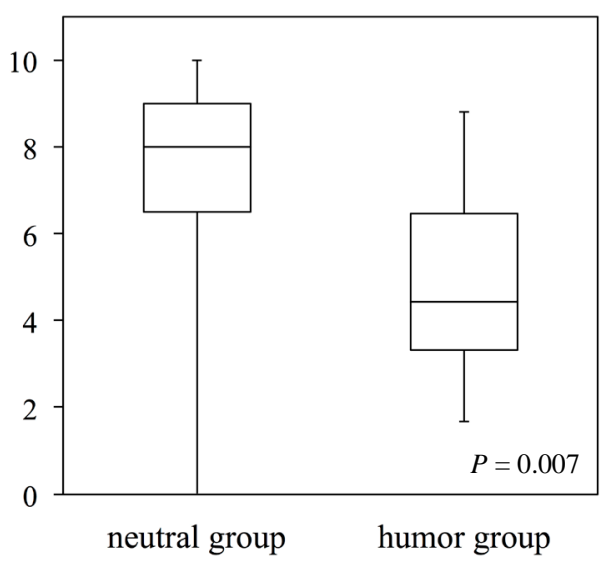

Figure 2. Box-and-whisker plot obtained from visual analog scale scores indicating the degree of pain in the neutral and humor groups.

by laughing frequently and focusing on the funny video. With regard to the pain experienced during mammography, the difference between the neutral and humor groups was statistically significant, suggesting the possibility of alleviating pain by humorous stimuli. However, we did not find a significant correlation between pain and comicality nor was there a correlation between pain and distraction. One reason for these negative results could be that only one type of video was prepared. We note that this observation is based on the assumption that the degree of pain relief depends on the strength of the stimulus of the humor. In order to prove this assumption, further study is needed. However, it may be that the strength of the humorous stimuli and the degree of pain relief are not correlated such that even a low stimulus level could be sufficient to alleviate pain effectively.

As an additional experiment, 14 women of the humor group also underwent conventional mammography (MLO of the right breast excluding X-ray irradiation) without exposure to the funny video and pain was assessed by VAS. The VAS score was $5.7 \pm 2.2$. In the humor group, pain experienced during conventional mammography without the funny video was weighed against pain experienced during the same mammography with the funny video. According to the Student's t-test, the difference between the two was statistically significant $(P=0.047)$. Results of this additional experiment suggest more strongly that humorous stimuli were effective in alleviating pain during mammography.

This study has several limitations. Participants had no choice regarding the type of comical clips they preferred to view and the sense of humor among individuals was not considered. Further, the number of subjects might have not been sufficient to power all of the statistical analyses. We performed the sham mammography by using only MLO of the right breast. Therefore, several independent examinations would be needed to overcome these limitations and they would provide stronger evidence of the effects of humorous stimuli in alleviating pain during mammography.

\section{Conclusion}

We examined the possibility that humor stimuli would alleviate the physical burden on women undergoing mammography. We found that the intensity of pain experienced during mammography was significantly reduced for patients who watched a funny video. Therefore, our findings suggested the possibility of alleviating pain during mammography by humorous stimuli.

\section{Acknowledgements}

The authors thank Sanae Hata for assisting with experiments and Prof. Du-Yih Tsai for support and discussion. This work was supported by JSPS KAKENHI Grant Number 23593285, 26463372.

\section{References}

[1] Drukker, B.H. (1997) Breast Disease: A Primer on Diagnosis and Management. International Journal of Fertility and 
Women's Medicine, 42, 278-287.

[2] Kerlikowske, K., Grady, D., Rubin, S.M., Sandrock, C. and Ernster, V.L. (1995) Efficacy of Screening Mammography. A Meta-Analysis. Journal of the American Medical Association, 273, 149-154. http://dx.doi.org/10.1001/jama.1995.03520260071035

[3] Aro, A.R., Absetz-Ylöstalo, P., Eerola, T., Pamilo, M. and Lönnqvist, J. (1996) Pain and Discomfort during Mammography. European Journal of Cancer, 32, 1674-1679. http://dx.doi.org/10.1016/0959-8049(96)00140-2

[4] Kornguth, P.J., Keefe, F.J. and Conaway, M.R. (1996) Pain during Mammography: Characteristics and Relationship to Demographic and Medical Variables. Pain, 66, 187-194. http://dx.doi.org/10.1016/0304-3959(96)03057-6

[5] Asghari, A. and Nicholas, M.K. (2004) Pain during Mammography: The Role of Coping Strategies. Pain, 108, $170-179$. http://dx.doi.org/10.1016/j.pain.2003.12.022

[6] Hafslund, B. (2000) Mammography and the Experience of Pain and Anxiety. Radiography, 6, 269-272. http://dx.doi.org/10.1053/radi.2000.0281

[7] Sapir, R., Patlas, M., Strano, S.D., Hadas-Halpern, I. and Cherny, N.I. (2003) Does Mammography Hurt? Journal of Pain and Symptom Management, 25, 53-63. http://dx.doi.org/10.1016/S0885-3924(02)00598-5

[8] Haus, A.G. (2002) Historical Technical Developments in Mammography. Technology in Cancer Research and Treatment, 1, 119-126. http://dx.doi.org/10.1177/153303460200100204

[9] Ng, K.H., Jamal, N. and De Werd, L. (2006) Global Quality Control Perspective for the Physical and Technical Aspects of Screen-Film Mammography_Image Quality and Radiation Dose. Radiation Protection Dosimetry, 121, 445451. http://dx.doi.org/10.1093/rpd/ncl051

[10] Robson, K.J. (2010) Advances in Mammographic Imaging. British Journal of Radiology, 83, 273-275. http://dx.doi.org/10.1259/bjr/97865299

[11] Yamada, T. (2010) Current Status and Issues of Screening Digital Mammography in Japan. Breast Cancer, 17, 163168. http://dx.doi.org/10.1007/s12282-009-0191-z

[12] Davey, B. (2007) Pain during Mammography: Possible Risk Factors and Ways to Alleviate Pain. Radiography, 13, 229-234. http://dx.doi.org/10.1016/j.radi.2006.03.001

[13] Sharp, P.C., Michielutte, R., Freimanis, R., Cunningham, L., Spangler, J. and Burnette, V. (2003) Reported Pain Following Mammography Screening. Archives of Internal Medicine, 163, 833-836. http://dx.doi.org/10.1001/archinte.163.7.833

[14] Keel, K.D. (1948) The Pain Chart. Lancet, 2, 6-8. http://dx.doi.org/10.1016/S0140-6736(48)91787-5

[15] Turk, D.C. and Melzack. R. (2001) Handbook of Pain Assessment. 2nd Edition, The Guilford Press, New York.

[16] Merzack, R. (1975) The McGill Pain Questionnaire: Major Properties and Scoring Methods. Pain, 1, 277-299. http://dx.doi.org/10.1016/0304-3959(75)90044-5

[17] Majani, G., Tiengo, M., Giardini, A., Calori, G., De Micheli, P. and Battaglia, A. (2003) Relationship between MPQ and VAS in 962 Patients. A Rationale for Their use. Minerva Anestesiologica, 69, 67-73.

[18] Uchiyama, M., Lee, Y., Sadakata, M., Sayama, M. and Tsai, D.Y. (2012) Measurement of Muscle Activities for Evaluating Physical Burden and Pain during Mammography Positioning. Tohoku Journal of Experimental Medicine, 228, 53-58.

[19] Uchiyama, M., Lee, Y., Sadakata, M., Tsai, D.Y. and Sayama, M. (2015) Quantification of the Pain and Physical Burden Experienced during Positioning for Craniocaudal Imaging in Mammography, Evaluated by Measurement of Muscle Activity. Health, 7, 23-34. http://dx.doi.org/10.4236/health.2015.71004

[20] Uchiyama, M., Lee, Y., Sadakata, M., Kazama, K., Minagawa, Y. and Tsurumaki, M. (2013) Effects of Mammography Positioning on the Autonomic Nervous Function. Health, 5, 1335-1341. http://dx.doi.org/10.4236/health.2013.58181

[21] Tabar, L., Lebovic, G.S., Hermann, G.D., Kaufman, C.S., Alexander, C. and Sayre, J. (2004) Clinical Assessment of a Radiolucent Cushion for Mammography. Acta Radiologica, 45, 154-158.

[22] Markle, L., Roux, S. and Sayre, J.W. (2004) Reduction of Discomfort during Mammography Utilizing a Radiolucent Cushioning Pad. Breast Journal, 10, 345-349. http://dx.doi.org/10.1111/j.1075-122X.2004.21352.X

[23] Kornguth, P.J., Rimer, B.K., Conaway, M.R., Sullivan, D.C., Catoe, K.E., Stout, A.L. and Brackett, J.S. (1993) Impact of Patient-Controlled Compression on the Mammography Experience. Radiology, 186, 99-102. http://dx.doi.org/10.1148/radiology.186.1.8416595

[24] Cousins, N. (1976) Anatomy of an Illness (as Perceived by the Patient). New England Journal of Medicine, 295, 14581463. http://dx.doi.org/10.1056/NEJM197612232952605

[25] Martin, R.A. (2001) Humor, Laughter, and Physical Health: Methodological Issues and Research Findings. Psychological Bulletin, 127, 504-519. http://dx.doi.org/10.1037/0033-2909.127.4.504 
[26] Mora-Ripoll, R. (2010) The Therapeutic Value of Laughter in Medicine. Alternative Therapies in Health and Medicine, 16, 56-64.

[27] Adams, E.R. and McGuire, F.A. (1986) Is Laughter the Best Medicine? A Study of the Effects of Humor on Perceived Pain and Affect. Activities, Adaptation and Aging, 8, 157-175. http://dx.doi.org/10.1300/J016v08n03_17

[28] Rotton, J. and Shats, M. (1996) Effects of State Humor, Expectancies, and Choice on Postsurgical Mood and Self-Medication: A Field Experiment. Journal of Applied Social Psychology, 26, 1775-1794. http://dx.doi.org/10.1111/j.1559-1816.1996.tb00097.x

[29] Nove, O., Keinan, G. and Teshimovssky, A.M. (1993) Humor and Pain Tolerance. Humor: International Journal of Humor Research, 6, 71-88.

[30] Weisenberg, M., Tepper, I. and Schwarzwald, J. (1995) Humor as a Cognitive Technique for Increasing Pain Tolerance. Pain, 63, 207-212. http://dx.doi.org/10.1016/0304-3959(95)00046-U 